\title{
The 2nd International Conference on Water Resource and Environment (WRE 2016)
}

\author{
Shanghai, China. 23-26 July 2016
}

01

\section{The eco-toxicological effects of cadmium stress on five} ornamental plants

Zhouli Liu, Wei Chen, Xingyuan He, Shuai Yu, Weihang Ding

Key Laboratory of Forest Ecology and Management, Institute of Applied Ecology, Chinese Academy of Sciences, 72 Wenhua Road, Shenhe District, Shenyang 110016, People's Republic of China

Correspondence: Xingyuan He - forestry83@hotmail.com

BMC Ecology 2016, 16(Suppl 2):01

Cadmium $(\mathrm{Cd})$ is one of the most toxic heavy metals and has recently become a global concern. The eco-toxicological effects of $\mathrm{Cd}$ in soilplant system are attracting more and more attention. Now many studies are mainly related to the effects of $\mathrm{Cd}$ on herbs and crops, and less information is on ornamental plants. Therefore in the present study, the eco-toxicological responses of five ornamental plants (Lonicera japonica Thunb., Weigela florida cv. Red Prince, Ginkgo biloba L., Parthenocissus quinquefolia and Parthenocissus semicordata) to $\mathrm{Cd}$ were investigated. Five $\mathrm{Cd}$ treatment concentrations $\left(0,5,10,25\right.$ and $\left.50 \mathrm{mg} \mathrm{L}^{-1}\right)$ were set. The results showed that the difference of physiological and biochemical characteristics in the plants under different $\mathrm{Cd}$ concentrations, such as antioxidant enzyme activity, chlorophyll contents and cell membrance permeability. The maintenance of high superoxide dismutase (SOD), peroxidase (POD), catalase (CAT) and ascorbate peroxidase (APX) activities in L. japonica was observed along with the increased $\mathrm{Cd}$ concentration, suggesting that the plant had better tolerance than another four plants, and had strong internal detoxification mechanisms to $\mathrm{Cd}$ stress. The results will provide an important scientific reference for remediation and management of $\mathrm{Cd}$-contaminated soil.

Acknowledgements: This work was supported by the National Natural Science Foundation of China (41301340), the National Science \& Technology Pillar Program (2012BAC05B05), the key project of Chinese Academy of Sciences (KFZD-SW-302-01), and the major National Science \& Technology project "water pollution control and management" (2012ZX07202008) of China.

\section{2}

Study on the formation and release mechanisms of hydrogen sulfide in Longtan coal mine

Jianjun Liu ${ }^{1,2}$, Yuliang $\mathrm{Wu}^{1,3}$, Kaixiang Fan ${ }^{1,4}$

${ }^{1}$ State Key Laboratory of Oil and Gas Reservoir Geology and Exploitation (Southwest Petroleum University), Chengdu, 610500, Sichuan, China;

${ }^{2}$ School of Geoscience and Technology, Southwest Petroleum University, Chengdu, 610500, Sichuan, China; ${ }^{3}$ Technology Center, Sichuan Coal Industry Group Limited Liability Company, Chengdu, 610091, Sichuan, China; ${ }^{4}$ School of Civil Engineering and Architecture, Southwest

Petroleum University, Chengdu, 610500, Sichuan, China

Correspondence: Jianjun Liu - liujj0906@sina.com

BMC Ecology 2016, 16(Suppl 2):02
In order to reveal the formation and release mechanisms of hydrogen sulfide $\left(\mathrm{H}_{2} \mathrm{~S}\right)$ in Longtan coal mine, and provide theoretical guidance for safety production, based on the geochemistry theory and series experiments of $\mathrm{H}_{2} \mathrm{~S}$ release, some important mechanism and laws were investigated. $\mathrm{H}_{2} \mathrm{~S}$ in coal seam of Longtan mine was formed by the dissimilatory reduction of sulfate reducting bacteria to sulfate. The proportion of abiogenic gas is very small in coal mass, but during the coal mining process, $\mathrm{H}_{2} \mathrm{~S}$ will be released because of the coal mass being broken and turned over; most $\mathrm{H}_{2} \mathrm{~S}$ exists in the formation water. When coal mining causes mine water pouring out, the water flow disturbance will induce $\mathrm{H}_{2} \mathrm{~S}$ dissolved in water releasing. The experiment results showed that with the water flow disturbance severity $\mathrm{H}_{2} \mathrm{~S}$ release rate increases. The release rate in water flow upstream is bigger than that of downstream. When the water flows to a certain distance, no $\mathrm{H}_{2} \mathrm{~S}$ releases from the water. Water $\mathrm{pH}$ value and temperature have some influence on the $\mathrm{H}_{2} \mathrm{~S}$ release, the lower the $\mathrm{pH}$ value, the higher the temperature, the more hydrogen sulfide is easy to escape from the water.

\section{3}

Coral bleaching in the North Reef of China's Xisha Islands in 2014

Yuanchao Li ${ }^{1}$, Xinqing Zheng ${ }^{2}$, Shiquan Chen ${ }^{1}$, Haiqun Xie ${ }^{1}$

${ }^{1}$ Hainan Academy of Ocean and Fisheries Sciences, Haihou 570100,

China; ${ }^{2}$ Third Institute of Oceanography, State Oceanic Administration,

Xiamen 361005, China

Correspondence: Yuanchao Li - lycouc@foxmail.com

BMC Ecology 2016, 16(Suppl 2):03

The North Reef (NR) is located in China's Xisha Islands in the Western Pacific, which contained successful coral reefs with a mean coverage that reached above $70 \%$ before 2013 because there was little anthropogenic disturbance. However, an investigation in October 2014 showed that large-scale coral bleaching had occurred on the flat and that the bleaching rate exceeded $90 \%$. The bleached corals were primarily Acropora formosa. Some of the bleached branches had been overgrown with microalgae and became yellow, indicating that the corals had bleached and died several months prior, and cannot recover, even if the sea surface temperature (SST) declines below $30{ }^{\circ} \mathrm{C}$. However, coral bleaching was not observed in the slope of the $\mathrm{NR}$, found in deeper waters. We speculate that the large-scale coral bleaching in the NR flat was predominantly triggered by elevations in SST. According to data from the Space Science and Engineering Center, the SST from June to September 2014 was above $30^{\circ} \mathrm{C}$, which could easily cause coral to bleach, and hermatypic corals, especially Acropora, to do so when SSTs exceed this threshold. The NOAA also found that the degree-heating weeks (DHW) reached $4{ }^{\circ} \mathrm{C}$-weeks in June 2014 and continued to rise, remaining above $8{ }^{\circ} \mathrm{C}$-weeks from July to September 2014. It peaked in September 2014 at $12{ }^{\circ} \mathrm{C}$-weeks. If the NR corals continue to be affected by high temperatures in 2015, as predicted by NOAA, the reef ecosystem will be further stressed, and large-scale coral mortality will be inevitable in the NR. 
Acknowledgements: This work was supported by Xiamen Southern Oceanographic Center, Contract No: 14CZY037HJ11.

\section{4}

Soil chemical characteristics in a Cunninghamia lanceolata stand suffering from ice-snow damage

Jie Li, Zhuomin Wang, Li Xue

College of Forestry and Landscape Architecture, South China Agricultural University, Guangzhou 510642, China

Correspondence: Li Xue - forxue@scau.edu.cn

BMC Ecology 2016, 16(Suppl 2):04

Studies on soil chemical characteristics were conducted in a Cunninghamia lanceolata stand suffering from ice-snow damage in the north of Guangdong province from 2008 to 2011. The results showed that the $\mathrm{pH}$ of the upper soil layer $(0-20 \mathrm{~cm})$ and lower soil layer $(20-$ $40 \mathrm{~cm}$ ) decreased with increasing time. The organic matter content of the upper soil layer increased significantly and then decreased very significantly, whereas that of lower layer decreased significantly. The change tendency of total $\mathrm{N}$ content was similar to the organic matter. Total P content of the two soil layers increased significantly, and then decreased very significantly. Total $K$ of the two soil layers decreased with increasing time. Contents of Alkahi-hydrolyzable $\mathrm{N}$, available $\mathrm{P}$, available $\mathrm{K}$ of the upper soil layer were greater than those of the lower layer in each year. Urease activity of the upper soil layer decreased, whereas that of lower layer decreased, and then increased. Activities of phosphatase and catalase decreased and then increased.

05

Diversity of understory vegetation was under a Cunninghamia lanceolata stand suffering from ice-snow damage

Zhiyang Lie, Weilong Huang, Tongtong Zhou, Li Xue

College of Forestry and Landscape Architecture, South China Agricultural University, Guangzhou 510642, China

Correspondence: Li Xue - forxue@scau.edu.cn

BMC Ecology 2016, 16(Suppl 2):05

Diversity of understory vegetation was studied in a Cunninghamia lanceolata stand suffering from ice-snow damage in the north of Guangdong province from 2008 to 2011. The species in shrub layer increased, and most plants were shade-tolerance plants in the herbaceous plant layer from 2009. Rubus rosaefolius became the absolute dominant species in the shrub layer in 2010, and some new species, such as Aster ageratoides and Dryopteris podophylla appeared in herbaceous plant layer. The herbaceous plants occupied dominion position when the ice-snow damage occurred in 2008 , and then many kinds of shadetolerance shrubs invaded one after another. Richness index of the shrub layer under the C. lanceolata stand in 2009 was the lowest during 3-year study course. Simpson index in 2009 was larger than that in 2010, whereas Shannon-Wiener index was opposite. Richness index of the herbaceous plant layer under the stand in 2008 was compared to those in 2009 and 2010. The order of Simpson and Shannon-Wiener index indices of the 3 years were 2009, 2010, 2008. Therefore, the species diversity in 2009 was the highest and the stablest with well-distributed species.

06

The effect of water, nitrogen and harvesting time on yield and biomass allocation of Helianthus tuberosus $\mathrm{L}$.

Kai Gao, Tiexia Zhu

Inner Mongolia University for Nationalities, Tongliao, 028043, Inner

Mongolia, China

Correspondence: Kai Gao - gaokai555@126.com

BMC Ecology 2016, 16(Suppl 2):06

With the study on the effect of nitrogen fertilization (five fertilization levels), irrigation (including irrigation and without irrigation) and harvesting time (including September 25 and October 10) on height, biomass and the role of mater allocation of Helianthus tuberosus L. in north-eastern Inner Mongolia, China, the results showed that the height and yield of $H$. tuberosus L. were significantly improved by irrigation and nitrogen fertilization + irrigation $(p<0.05)$. Nitrogen fertilizer significantly influence height and yield during irrigation and achieved higher yield during addition of nitrogen $\left(25-50 \mathrm{~kg} \mathrm{ha}^{-1}\right)$ $(p<0.01)$. On the contrary, it was not significantly influenced without irrigation. Helianthus tuberosus L. was early harvested when it was used for forage, and it was lately harvested when it was used for bio-ethanol and inulin; The root/shoot ratio and tuber mass ratio were significantly improved under fertilizer, water and nitrogen fertilizer + water condition $(p<0.05)$; The leaf mass ratio was remarkably improved under nitrogen fertilizer, water and nitrogen fertilizer + water condition during nutritional growth, and it did not indicate significant difference after nutritional growth; The growth, the yield, the water use efficiency and the yield of tuber were enhanced by the application of nitrogen fertilizer and water, and the using value for energy was improved by nitrogen fertilization and irrigation.

Acknowledgements: The National Natural Science Foundation project, Project Number 31560672.

07

The vertical variation of microbial communities in the sediment of sea cucumber pond

Weiteng Mao', Pei Yu', Xinfang LV $v^{1}$, Yunchun $\mathrm{Li}^{1,2}$

${ }^{1}$ Marine College, Shandong University, Weihai 264209, China; ${ }^{2}$ Institute of Ecology and Biodiversity, Shandong University, Jinan 250100, China

Correspondence: Xinfang Lv - Ivxinfang@hotmail.com

BMC Ecology 2016, 16(Suppl 2):07

The sediment of aquaculture pond has important influence on the water quality and the health of sea cucumber (Apostichopus japonicas Selenka). We collected the sediment in a sea cucumber pond which is located in Rongcheng and divided it into 9 samples named from L1 $(0-3 \mathrm{~cm})$ to $\mathrm{L9}(24-27 \mathrm{~cm})$. The environmental factors of all samples have been measured, with the 16SrDNA sequencing by the illumina miseq to detect the microbial communities in the samples L1, L2, L6 and L9. The sediment has the characteristics of high-organic-matter, high-nitrogen, high-sulfur and low-phosphate. The dominant bacteria are the phylum proteobacteria, acidobacteria, bacteroidetes, chloroflexi, planctomycetes, gemmatimonadetes and nitrospirae. The content of bacteroidetes tends to decrease with the increase of sediment depth, while the contents of chloroflexi, gemmatimonadetes and nitrospirae show the opposite tendency. PCA analysis and SPSS correlation analysis show that the microbial communities are mainly affected by phosphorus and salinity. The abundant sequences of probiotics were detected in our study such as photosynthetic bacteria (PSB), nitrifying bacteria, bacillus and bdellovibrio. Our study takes a new look at the sterilization in the aquaculture of sea cucumber and provides theoretical guidance for the exploitation and application of probiotics.

08

Indicating significances of alpine plant functional groups

to environmental change

Peixi Su, Rui Shi

Cold and Arid Regions Environmental and Engineering Research Institute,

Key Laboratory of Land Surface Process and Climate Change in Cold and Arid Regions, Chinese Academy of Sciences, Lanzhou 730000, China Correspondence: Peixi Su - supx@|zb.ac.cn

BMC Ecology 2016, 16(Suppl 2):08

Alpine plants on the Zoige Plateau in the Eastern Qinghai-Tibetan Plateau of China were divided into five functional groups based on hydro-ecological characteristics and $\delta^{13} \mathrm{C}$ value using an ecological investigation employing horizontal and vertical belt transects (listed here from dry to wet habitats): xeromesophytes, mesophytes, hygromesophytes, hygrophytes and hydrophytes. Plants were also divided by physiognomic life form and classification features into six 
groups: tree, shrub, grass, sedge, weed and aquatic species. Based on Raunkiaer's classification system, which classifies plant adaptation into harsh and cold environments, the alpine plants were divided into five groups: phanerophytes, chamaephytes, hemicryptophytes, geophytes, and therophytes. Hemicryptophytes and geophytes accounted for $66 \%$ of the total alpine plant species on the Zoige Plateau, of which perennial herbaceous plant species take $89 \%$ of the total number of herbaceous plant species. In alpine plant community regressive succession with water environment deteriorating, from wetland, swampy meadow, wet meadow, dry meadow, to degraded meadow phase, hygrophytes were replaced by mesophytes and xeromesophytes. Over time increasingly abundant dominant grass species displaced dominant sedge species with less abundance. Dicotyledonous weed plants were dominant in highly degraded meadow, and increased in abundance during succession. Succession tended to move from alpine meadow to alpine shrubby meadow.

\section{9}

Research on the daily $\mathrm{CH}_{4}$ fluxes of soil in summer mangrove community at Yingluogang of Guangxi, China

Yong Jiang ${ }^{1,2}$, Xingbin Chen ${ }^{1,2}$, Shichu liang ${ }^{1,2}$

${ }^{1}$ College of Life Science, Guangxi Normal University, Guilin, 541004, Guangxi China; ${ }^{2}$ Key Laboratory of Ecology of Rare and Endangered Species and Environmental Protection (Guangxi Normal University), Ministry of Education, Guilin 541004, China

Correspondence: Shichu liang - gxlsc@sina.com

BMC Ecology 2016, 16(Suppl 2):09

Mangrove ecosystems are known sources for methane $\left(\mathrm{CH}_{4}\right)$ having very high global warming potential on global change. In order to better understand $\mathrm{CH}_{4}$, dynamics will affect global change in wetland system. We have quantified the daily $\mathrm{CH}_{4}$ fluxes for various species within mangrove wetland communities (Kandelia candel, Bruguiera gymnorhiza, Rhizophora stylosa and Aegiceras corniculata communities) in southwest China. Additionally, we evaluated the influence of different environmental factors (air temperature, soil temperature, soil pH and salinity) on daily $\mathrm{CH}_{4}$ fluxes. According to the measurements from a portable automated flux system, the mean fluxes of the daily $\mathrm{CH}_{4}$ were the lowest in B. gymnorhiza community, the higher in Aegiceras corniculatum and $A$. corniculata community, and the highest in the $K$. candel community. Variation in fluxes of the daily $\mathrm{CH}_{4}$ was mainly determined by soil $\mathrm{pH}$ among the four communities in the summer. Daily $\mathrm{CH}_{4}$ fluxes were positively related to soil pH in $R$. stylosa community and negatively related to soil $\mathrm{pH}$ in $\mathrm{A}$. corniculata community; however, $\mathrm{pH}$ was uncorrelated with $\mathrm{CH}_{4}$ fluxes in either $K$. candel or $B$. gymnorhiza communities. We draw conclusion that significant differences in daily $\mathrm{CH}_{4}$ fluxes are linked to soil $\mathrm{pH}$ in several mangrove wetland communities.

Acknowledgements: This work was supported by fund for key research project of natural science foundation of Guangxi (2012 GXNSFEA 053001).

\section{0}

Beach protection structures in middle and lower reaches of Yangtze River

Junfeng Xu

Tianjin Research Institute for Water Transport Engineering, Key Laboratory of Engineering Sediment, Ministry of Transport, Tanggu, Tianjin 300456,

China

Correspondence: Junfeng Xu - 13920354156@139.com

BMC Ecology 2016, 16(Suppl 2):10

Lots of beach protection measures have been taken in the middle and lower Yangtze River, such as fish-born dikes, soft mattresses, mesh pads and tetrahedron-like penetrating frames. These structures of beach protection can realize basic functions. But for the ecological protection of the river, there is a certain distance. The existing river ecological engineering researches mainly include the ecological environmental protection building materials and vegetation beach protection technology. Based on the practical effect, the commonly used traditional building material has a higher maintenance cost, which does not have the ecological function and poor landscape effect. Through the model test, the most easily damaged parts and the main failure reasons of these structures and measures to prevent damage and relevant restoration measures are also analyzed in the paper. The effect of a new kind of beach protection structure applied in Middle and Lower Reaches of Yangtze River is analyzed and the adaptability of this new structure is concluded. It serves as reference for similar projects.

Acknowledgements: This research was supported by funding from The central level, scientific research institutes for basic R \& D special fund business (TKS150102).

\section{1}

Social responsibility management of large dam project with owner as core: an empirical case in China

Jiwei Zhu' ', Zhao Zhai ${ }^{2}$, Linan Zhou' ${ }^{1}$, Yun Le ${ }^{2}, \mathrm{Li} \mathrm{CaO}^{3}$

${ }^{1}$ State Key Laboratory of Ecological Water Conservancy in the Northwest Arid Area, Xi'an University of Technology, Xi'an, 710048, China; ${ }^{2}$ Research Institute of Complex Engineering and Management, Tongji university, Shanghai 200092, China; ${ }^{3}$ China Three Gorges Corporation, Beijing

100038, China

Correspondence: Jiwei Zhu - zhujiwei@xaut.edu.cn

BMC Ecology 2016, 16(Suppl 2):11

As major infrastructure project, the large dam project (LDP) has functions such as flood control, power generation, irrigation, water supply and so on. LDP could lead to a series of ecological and social effects due to the potential inundation, resettlement, and change of hydrological regime. How to reduce its negative effects and ensure public interests is the key issue to promote LDP management and sustainable development. The owner as an investor is the core role to undertake the society responsibility of LDP. Based on the analysis of relationship among various stakeholders, we propose a management framework of social responsibility of large dam project (LDP-SR), which includes three dimensions: responsibility, organization and project life-cycle. We also establish the evaluation index system of LDP-SR for the owner by adopting corporate social responsibility (CSR). Taking the Three Gorges Project in China as an example, the social responsibility performance is evaluated by using the AHP-MF model. The research findings contribute to knowledge of stakeholder management of LDP-SR and provide a solution for the owner of LDP to fulfill social responsibility and promote sustainable development.

\section{2}

The ecological function value assessment analysis of urban waterfront

Jiwei Zhu', Ping Lu', Zhiqian Huang ${ }^{2}$, Bei Zhou'

${ }^{1}$ State Key Laboratory of Ecological Water Conservancy in the Northwest Arid Area, Xi'an University of Technology, Xi'an 710048, China; ${ }^{2} \mathrm{Ji}$ 'nan City Construction Investment Group Corporation Limited, Ji'nan 250101, China

Correspondence: Jiwei Zhu - zhujiwei@xaut.edu.cn BMC Ecology 2016, 16(Suppl 2):12

Taking unbar waterfront in Xi'an-Chan Ba wetland as an example, this paper establishes the ecological function value evaluation index system to study on function value of urban waterfront ecosystem. This paper calculates and researches ecological function value by using some mathematic and economic method, such as the market value method, carbon tax method,the afforestation cost method, the alternative cost method, the shadow engineering method, ecological value method, and traveling cost method. Through calculation, the ecological function value of Chan-Ba wetland is $¥ 3.87 \times 10^{8}$, in which the ratio of material production function, ecological regulation function and social service function value was 3.65, 38.59, $57.76 \%$, respectively. The value of Chan-Ba wetland is a rational combination between environmental protection and function of science, education 
and entertainment. Urban waterfront ecological function value has an important position in the urban economic and social development and ecological construction. Only when reasonable development and protection of the urban waterfront ecological environment can the effective utilization of resources be achieved and sustainable development of urban economy be ensured.

13

Mechanism of diurnal osmotic potential changes and adjustment of three Caragana species in different habitats of the Inner Mongolia Plateau

Zhirong Zheng ${ }^{1,2}$, Shihai Lv $v^{2}$, Chaoyang Feng ${ }^{2}$

${ }^{1}$ College of Life Science, Nankai University, Tianjin 300071, People's Republic of China; ${ }^{2}$ State Environmental Protection Key Laboratory of Regional Eco-process and Function Assessment, Chinese Research Academy of Environmental Sciences, Beijing 100012, People's Republic of China

Correspondence: Chaoyang Feng - fengchy@craes.org.cn

BMC Ecology 2016, 16(Suppl 2):13

Plants belonging to the genus Caragana are selected as preferred legume shrubs for water conservation and sand fixation in the arid and semi-arid areas of the Mongolian Plateau. The distributions of three Caragana species (Caragana microphylla, Caragana davazamcii, and Caragana korshinskii) exhibit remarkable regional-level distribution characteristics, whereby they replace each other along a longitudinal water gradient from east (semi-arid habitat) to west (arid habitat). We investigated the cell water relations for this substituted distribution by: (1) comparing diurnal variation in osmotic potential, and (2) analyzing the relative contributions of three regulatory mechanisms to diurnal variation in osmotic potential. We found that dehydration and intracellular net solute accumulation were the main regulatory mechanisms used by all three Caragana species to adjust diurnal variation in osmotic potential. The relative contribution of dehydration to osmotic potential changes of C. microphylla, C. davazamcii and C. korshinskii was 76, 56, and $52 \%$, respectively, while that of net solute accumulation was 38,39 , and $34 \%$, respectively. As drought conditions increased, the regulating capacity of cell water gradually increased from C. microphylla to C. davazamcii and C. korshinskii, forming the stable physiological basis for their substituted distribution on the Mongolian Plateau.

\section{4}

Biodiversity of phytoplankton and environmental influences analysis of Longfeng Wetland, China

Nan Song, Yan Liu, Xinxin Lu, Yawen Fan

College of Life Science and Technology, Harbin Normal University, Harbin, Heilongjiang, People's Republic of China

Correspondence: Yawen Fan - fanyaw@163.com

BMC Ecology 2016, 16(Suppl 2):14

The water quality of Longfeng Wetland was surveyed in 2011 to investigate the relationship between phytoplankton and environmental variables in the present study. Data of environmental conditions of five sites were different, the highest quality of the water was observed at site 2. A total of 99 genera of phytoplankton were identified, which belonged to 8 phyla and 47 families. Cyanophyta was absolutely dominant (approximately $47.56 \%$ of total), and Bacillariophyta represented $18.05 \%$ of total, showing that Longfeng Wetland was a Cyanophyta-Bacillariophyta predominant wetland. The highest number of genera of phytoplankton community was present in places with turbulent water (site 4) and scenic spot (site 2). The multimetric indexes indicated that this place was less influenced from August to September. The most dominant species were Nitzschia palea and Cyclotella meneghiniana in Longfeng Wetland, which belonged to Bacillariophyta. The canonical correspondence analysis (CCA) showed that the SpCond, TN, BOD5, and CODcr were the most effective environmental factors and having the greatest influence on the dominant species. In addition, $\mathrm{pH}$ and $\mathrm{DO}$ had considerable influence on Scenedesmus dimorphus. Our findings may imply that the biomass of $N$. palea and S. dimorphus can be used as biological quality indicators in wetland.

Acknowledgements: This work were supported by NSFC( 31270250 31470308) and the Graduate Innovative Research Projects of Heilongjiang Province (No. YJSCX2011-412HLJ).

15

The effect of human activities on culturable soil microbes from Yaoquan Mountain in Wudalianchi, China

Jianfei Guan ${ }^{1}$, Jihua Wang ${ }^{2}$, Xueping Zhang ${ }^{1}$

${ }^{1}$ College of Geographical Science, Harbin Normal University, Harbin,

Heilongjiang, 150025, China; ${ }^{2}$ College of Life Science and Technology,

Harbin Normal University, Harbin, 150025, Heilongjiang, China

Correspondence: Jihua Wang - wangjihua333@hotmail.com

BMC Ecology 2016, 16(Suppl 2):15

The effect of human activities on the soil microbial community structure and the relationships among microbial community members, soil chemical properties, and enzyme activity levels were assessed using soil samples from Yaoquan Mountain in Wudalianchi, China. Soil cultures revealed Bacillus, Streptomyces, Aspergillus, and Penicillium which were common microbial species in Yaoquan Mountain soil samples. The degree of human disturbance was negatively correlated with disturbance in the microbial community composition, so that quantitative changes in the representation of actinomycetes and fungi were more sensitive to human activities than that of bacteria. The survey also revealed spatial heterogeneity in soil microorganisms. Within a given sampling area of the mountain, the separation frequency of some strains changed clearly with the increases in disturbance. Accordingly, Enterobacter and Penicillium may be used as indicative bacteria for evaluating human disturbance on mountaintops, while Aspergillus, Penicillium, Lactobacillus, and Streptomyces are better suited for evaluating human disturbance on mountainsides. Soil organic matter, total nitrogen, catalase, and cellulase levels each exhibited extremely significant correlations with the level of human disturbance. Organic matter, catalase activity, cellulase activity, and $\mathrm{pH}$ greatly influenced the microbial community structure. By revealing the quantity and structure of microorganisms and their relationship with environmental factors, this research has characterized the effect of human disturbance on Yaoquan Mountain.

Published: 7 November 2016 